\title{
ORIGINAL RESEARCH \\ Diffusion Changes in the Vitreous Humor of the Eye during Aging
}

i. Meral
Y. Bilgili

BACKGROUND AND PURPOSE: The inability to image the vitreous humor of the eye adequately hinders a complete understanding of its normal structure and the changes occurring in aging and disease. The purpose of the present study was to reveal normative data and age-related changes of the vitreous humor by using DWI.

\begin{abstract}
MATERIALS AND METHODS: A total of 160 patients were enrolled in the present study. Patients were divided into 8 groups according to decade of age, and each group was of equal size with 20 patients. The ADCs were determined for each vitreous humor. Each determination was obtained by using average regions of interest of $50 \pm 2 \mathrm{~mm}^{2}$. ADC values were then plotted against age.
\end{abstract}

RESULTS: The ADC values obtained from group 0 ( $0-10$ years of age) were statistically different from those of all other groups $(P<.05)$. Group 1 (11-20 years of age) was statistically different from groups $3,5,6$, and $7(P<.05)$. A trend toward increased ADC values with increasing age was not statistically significant.

CoNCLUSIONS: Besides the statistically significant difference between pediatric and adult patients, a statistically insignificant trend of increased ADC values among aging adults has been demonstrated. These normative data contribute to our understanding of how DWI can aid in the diagnosis of age-related changes in eye health and function.

ABBREVIATIONS: $A D C=$ apparent diffusion coefficient; $D W I$ = diffusion-weighted imaging; $O C T=$ optical coherence tomography; SLO = scanning laser ophthalmoscopy

D uke-Elder ${ }^{1}$ once described the structure of the vitreous humor of the eye as "composed of loose and delicate filaments surrounded by fluid," a description that is remarkably close to an understanding of present day concepts.

The vitreous gel, maintained by a low-attenuation network of collagen fibrils, is homogeneous, with no liquefaction at all in the eyes at infancy, but undergoes age-related changes that increase its liquefaction..$^{2-4}$ The mechanism involves a breakdown of the network of collagen fibrils, and this appears to be crucial for the age-related liquefaction of the human vitreous humor. ${ }^{4}$

Classic and modern histologic examinations, dark-field slit microscopy, clinical slit-lamp biomicroscopy, standard laser ophthalmoscopy and SLO, sonography, OCT, combined OCT-SLO, MR imaging, Raman spectroscopies, and dynamic light scattering are all techniques that have been reported in the study of the structure and function of the vitreous humor. ${ }^{5}$ It is believed that the development of a tool for the adequate imaging of the vitreous humor will only be accomplished by combining the use of more than 1 technique; therefore, there is a rationale for the exploration of new methods. ${ }^{5,6}$

DWI is an MR imaging technique that provides image contrast related to the random microscopic motion of water protons. Diffusion depends on a variety of biophysical properties in tissue, including cell organization, attenuation, microstructure, and microcirculation, all of which change with age in the

Received November 13, 2010; accepted after revision December 22.

From the Department of Radiology, Kirikkale Universitesi Medicine Faculty, Kirikkale, Turkey.

Please address correspondence to Yasemin Bilgili, MD, Sevil sokak 16/3 06590, Cebeci, Ankara, Turkey; e-mail: mykaradeniz@hotmail.com

http://dx.doi.org/10.3174/ajnr.A2543 vitreous humor. ${ }^{7,8}$ Thus, DWI may be able to detect age-related changes in the vitreous humor.

The purpose of this study was to obtain normative data detailing the ADC of the vitreous humor in children and adults across a spectrum of ages.

\section{Materials and Methods}

The ethics committee of our university approved the protocol for the involvement of human subjects in this study. Informed consent was obtained from subjects or their legal guardians.

First, we defined 8 decadic age groups and then enrolled patients until we had 20 patients in each group, so a total of 160 patients were prospectively included in the present study. They were selected from patients undergoing clinical imaging studies.

The medical history of each patient was recorded. Patients were excluded from the study if their history included any of the following: vitreous hemorrhage, glaucoma, uncontrolled hypertension, or diabetes mellitus.

Also 2 radiologists (Y.B., I.M.) independently determined that MR imaging findings of each orbit were normal in all subjects.

All experiments were performed by using a head coil in conduction with a $1.5 \mathrm{~T}$ whole-body imager (Infinion; Philips Healthcare, Cleveland, Ohio) with a maximum gradient amplitude of $50 \mathrm{mT} / \mathrm{m}$ and a maximum gradient slew rate of $100 \mathrm{mT} / \mathrm{m} / \mathrm{s}$. The head coil had an inner diameter of $27 \mathrm{~cm}$. Before DWI, conventional T1- and T2weighted images were obtained in the transverse plane.

DWI was performed by using a single-shot spin-echo echo-planar sequence. During the MR imaging studies, the 2 radiologists (M.Y.K.B., I.M.) evaluated the quality of DWIs and selected, by consensus, the images for further analysis that had a minimum of distortion from susceptibility artifacts and ghosting. We selected $b$-values of 0 and $1000 \mathrm{~s} / \mathrm{mm}^{2}$ for calculation of ADC in this study. DWIs were obtained during 43 seconds. DWI was performed with the following 


\begin{tabular}{lc}
\hline Mean ADC values for each group & \\
\hline & $\begin{array}{c}\text { Mean ADC Value } \\
\left(\times 10^{-3} \mathrm{~mm}^{2} / \mathrm{s}\right) \\
(\text { range })\end{array}$ \\
\hline Decadic Age Groups (yr) & $3.02 \pm 0.07(2.88-3.16)$ \\
\hline Group $0(0-10)$ & $3.28 \pm 0.07(3.15-3.41)$ \\
Group $1(11-20)$ & $3.39 \pm 0.07(3.26-3.52)$ \\
Group $2(21-30)$ & $3.59 \pm 0.07(3.46-3.72)$ \\
Group $3(31-40)$ & $3.31 \pm 0.08(3.15-3.48)$ \\
Group $4(41-50)$ & $3.62 \pm 0.07(3.48-3.76)$ \\
Group $5(51-60)$ & $3.56 \pm 0.07(3.43-3.69)$ \\
Group $6(61-70)$ & $3.57 \pm 0.07(3.44-3.70)$ \\
Group $7(\geq 71)$ &
\end{tabular}

a The ADC values obtained from group 0 were statistically different from those in the other groups, whereas group 1 was statistically different from groups $3,5,6$, and $7(P<.05)$. An observable trend showing increasing ADC values with increased aging is not statistically significant.

parameters: TR/TE, $3469 / 92 \mathrm{~ms}$; flip angle, $90^{\circ}$; FOV , $230 \times 230 \mathrm{~mm}$; and matrix size, $128 \times 90 \mathrm{~mm}$. Between 20 and 25 axial sections were obtained, with a section thickness of $5 \mathrm{~mm}$ and an intersection gap of $1 \mathrm{~mm}$. The reconstructed magnitude images were transferred from the MR imaging system to an independent workstation for the calculation of the trace images and ADC values.

In a group of 20 patients, to establish internal control, ADC values were obtained from the CSF of the frontal horn of the lateral ventricles and compared with the values obtained from the vitreous, by using paired $t$ tests.

The data evaluators were blinded to the age of the patient when calculating ADC values for each vitreous humor. The mean values of the areas corresponding to a region of interest of $50 \pm 2 \mathrm{~mm}^{2}$ were calculated. Interobserver and intraobserver variability of ADC values were tested by using Cronbach $\alpha$. ADC values obtained from the vitreous humor of the right and left eyes in each patient were analyzed by using paired $t$ tests. Mean ADC values grouped in decadic ages of life were then compared by using multivariate analysis of variance. The significance level for assessing meaningful differences was $P<$ .05 .

\section{Results}

Our study population consisted of 160 patients, 74 males and 86 females, ranging in age from 2 months to 84 years. The mean age of all patients was $40 \pm 18$ years.

The internal control group consisted of 20 patients, 8 males and 12 females, ranging in age from 16 to 63 years with a mean age of $36.7 \pm 17$ years. The mean ADC value obtained from CSF was $3.48 \pm 0.05 \times 10^{-3} \mathrm{~mm}^{2} / \mathrm{s}$ (range, $2.35-4.31 \times 10^{-3}$ $\mathrm{mm}^{2} / \mathrm{s}$ ) and, for the vitreous, $3.35 \pm 0.02 \times 10^{-3} \mathrm{~mm}^{2} / \mathrm{s}$ (range $2.88-3.77 \times 10^{-3} \mathrm{~mm}^{2} / \mathrm{s}$ ). While the mean ADC value of the vitreous was lower than that of the CSF, the difference was not statistically significant $(P>.05)$.

The Table presents the mean (plus the measure of variation) of the ADC values obtained for all study patients organized into decadic age groups. Post hoc analysis of the mean ADC values revealed that those of group 0 ( $0-10$ years $)$ were statistically different from the mean ADC values of all other age groups $(P<.05)$ (Fig $1 A,-B)$. The mean ADC value observed in age group 1 (11-20 years) was found to be different from those of groups 3, 5, 6, and 7 as well $(P<.05)$. While the mean ADC values of groups 2 and 4 were seen to be higher than that in group 1, this difference was not statistically significant.

Differences in the ADC values between the right and left eyes of each patient were assessed and found not to be significantly different $(P>.05)$. Moreover, there were no statistically significant differences in the inter- or intraobserver ADC value determination ( $\alpha$ : 0.82 and 0.86 , respectively). While a trend could be observed in that ADC values increased with healthy patient age, the statistical significance of this correlation could not be established.

\section{Discussion}

The vitreous humor of the eye is composed of a transparent gel consisting almost entirely of the constituents that describe tissue extracellular matrix. It is composed largely of water with small amounts of essential structural macromolecules. ${ }^{9,10}$ The gel state of the vitreous humor is maintained by a low-attenuation network of long thin collagen fibrils. ${ }^{3}$

The vitreous gel, which is quite compositionally homogeneous with no relative liquefaction in infancy, undergoes noticeable age-related changes with the progress of years. ${ }^{2,4}$ Morphologically, 2 distinct structural alterations can be observed. ${ }^{4}$ On the 1 hand, there is a progressive increase in the volume of liquefied spaces (synchysis), and on the other, there is an increase in optically attenuated areas (syneresis). ${ }^{11-14}$ Collagen fibrils are an essential component of the vitreous gel structure, and with time, they break down into smaller fragments that are involved in the mechanism of the age-related liquefaction of the vitreous humor. ${ }^{4}$ With aging, these collagen fibrils progressively aggregate due to a loss of collagen components on the fibril surface necessary for maintaining a nonliquefied gelatinous state. In particular, hyaluronic acid is a major component of the vitreous gel, which contributes to gel viscosity, and both this substance and proteoglycans decrease in the
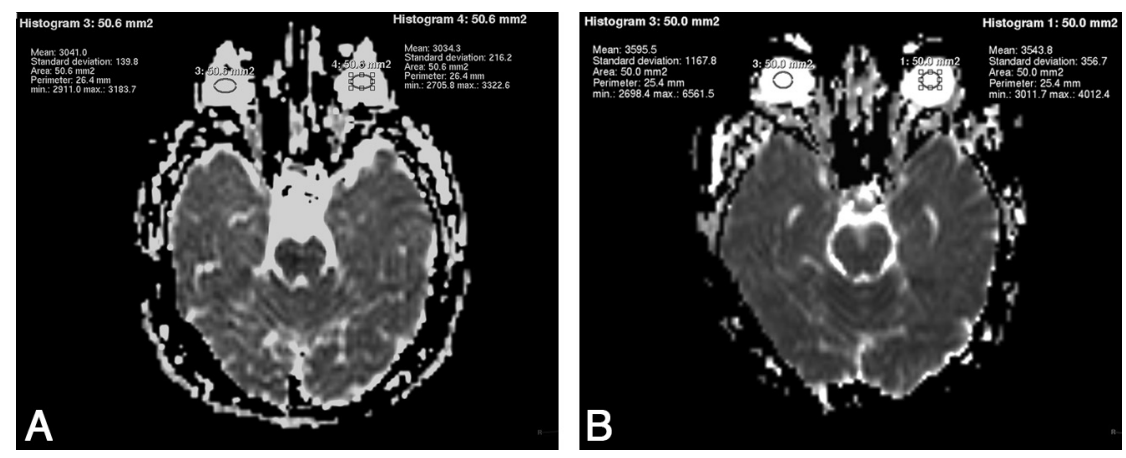

Fig 1. A, ADC values obtained from the vitreous of a 4-year-old girl (W 1524/L 762). B, ADC values obtained from the vitreous of a 54 -year-old man (W 1528, L 764). 


\section{$A D C$ values for age groups}

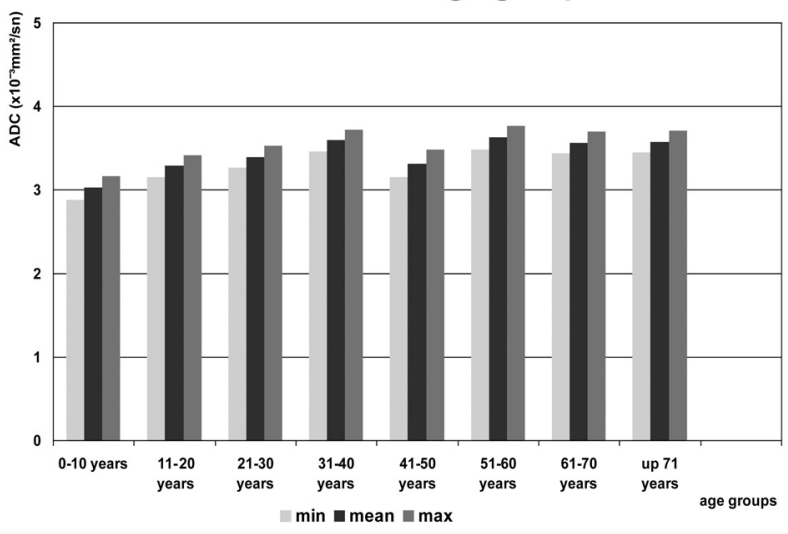

Fig 2. ADC values for age groups

contents of the gel and may explain age-related vitreous liquefaction. ${ }^{2,4}$

Diffusion is a physical property, which describes the microscopic random movement of (water) molecules driven by their internal thermal energy. Relative free or unimpeded diffusion is encountered in tissues with low cellularity or tissues with disrupted cell membranes, as in cysts and necrotic tissues. ${ }^{15,16}$

Diffusion can be quantitatively evaluated by using ADC, expressed in square millimeters per second. The ADC reflects diffusion properties within the tissue and depends on many physiologic parameters such as volume fractions, extracellular tortuosity, intracellular restrictions, membrane permeability, active processes across membranes, relaxation rates, or anisotropic morphology. ${ }^{17}$ A low ADC value implies a limited or restricted diffusion, and this is observed in tissues that are highly cellular. A high ADC value is more likely seen in structures in which tissue fluid has relatively free diffusion, in those with low cellularity, or in those that are cystic. ${ }^{15,16}$

DWI has been a complementary technique useful in the differential diagnosis of orbital pathologies such as orbital inflammatory syndrome, orbital lymphoid lesion, orbital cellulitis, acute optic nerve infarction, endophthalmitis, acute ischemic homonymous hemianopsia, indeterminate orbital masses, and optic neuritis. ${ }^{18-23}$ Also, Politi et $\mathrm{al}^{24}$ recorded the ADC of the vitreous humor in healthy subjects as part of a normative data collection for a larger study of orbital masses and found a mean vitreal ADC that is significantly lower than that in our results; the difference might be due to different techniques used in the studies.

According to our results, ADC values within first decade are statistically significantly different from those in all other age groups, and those in the second decade are statistically different from several but not all other age groups. Also, there is a statistically insignificant trend of increased ADC values with aging. Studies using microscopy have shown progressively larger vitreal spaces with age, and age-related increase in vitreal ADC values might be expected due to increased movement of fluid through these spaces. Also, it is widely believed that increased fluid viscosity is partially responsible for the low ADC observed in abscess cavities, and changes in viscosity likely account for the age-related changes in vitreal ADC observed in this study. ${ }^{25}$

However, on the basis of the results that are provided, be- yond a certain degree of vitreal liquefaction that occurs by the end of the second decade, DWI is unable to further characterize changes in the vitreous. This seems to be a limitation of the study. However, this normative data does have potential use for assessing patients with eye disease.

\section{Conclusions}

A better understanding of the normal physiology and structure of the vitreous humor of the eye and how changes in structure and function occur during aging and disease is necessary to develop more effective therapies and preventative care. ${ }^{5}$ Our use of DWI gave results that indicated a trend, though not statistically significant, showing increases in ADC values with advancing age, and we did find statistically significant difference between decadic age groups, namely between pediatric and adult patients. While DWI is unable to further characterize changes in the vitreous humor occurring by the end of the second decade of life, the normative data of the vitreous humor may play a complementary role not only for the differential diagnosis of ocular pathologies but also in contributing information to a large data base looking at how aging affects the vitreous humor.

\section{Acknowledgments}

We thank S.M.H. for proofreading the manuscript and making other helpful recommendations, as well as Can Bilgili and Selen Meral. Without their help this project could never have been completed.

\section{References}

1. Duke-Elder SW. The nature of the vitreous body. Brit J Ophthalmol 1930; 14(suppl 4):6

2. Itakura H, Kishi S, Kotajima N, et al. Decreased vitreal hyaluronan levels with aging. Ophthalmologica 2009;223:32-35

3. Bishop PN. Structural macromolecules and supramolecular organisation of the vitreous gel. Prog Retin Eye Res 2000;19:323-44

4. Los LI, van der Worp RJ, van Luyn MJA, et al. Age-related liquefaction of the human vitreous body: LM and TEM evaluation of the role of proteoglycans and collagen. Invest Ophthalmol Vis Sci 2003;44:2828-33

5. Sebag J. To see the invisible: the quest of imaging vitreous. Dev Ophthalmol 2008;42:5-28

6. Sebag J. Imaging vitreous. Eye 2002;16:429-39

7. Le Bihan $\mathrm{D}$, Breton $\mathrm{E}$, Lallemand $\mathrm{D}$, et al. Separation of diffusion and perfusion in intravoxel incoherent motion MR imaging. Radiology 1988;168:497-505

8. Bammer R. Basic principles of diffusion-weighted imaging. Eur J Radiol 2003;45:169-84

9. Bishop PN, Holmes DF, Kadler KE, et al. Age-related changes on the surface of vitreous collagen fibrils. Invest Ophthalmol Vis Sci 2004;45:1041-46

10. Bos KJ, Holmes DF, Meadows RS, et al. Collagen fibril organisation in mammalian vitreous by freeze etch/rotary shadowing electron microscopy. Micron 2001;32:301-06

11. Balazs EA, Denlinger JL. Aging changes in the vitreus. In: Sehuler R, Kline D, Dismukes K, eds. Aging and Human Visual Function. New York: Alan R. Liss; 1982:45-57

12. Szent-Gyorgyi A. Untersuchungen ub̈er den Bau des Glaskorpers des Menschen. Arch Anat 1917;89:324-86

13. Eisner G. Postmortem slitlamp study of the vitreous body. II. Pattern of vitreous structures made visible by the slitbeam. Albrecht Von Graefes Arch Klin Exp Ophthalmol 1971;182:8-22

14. Sebag J. Age-related changes in human vitreous structure. Graefes Arch Clin Exp Ophthalmol 1987;225:89-93

15. Charles-Edwards EM, deSouza NM. Diffusion-weighted magnetic resonance imaging and its application to cancer. Cancer Imaging 2006;6:135-43

16. Kwee TC, Takahara T, Ochiai R, et al. Diffusion-weighted whole-body imaging with background body signal suppression (DWIBS): features and potential applications in oncology. Eur Radiol 2008;18:1937-52. Epub 2008 Apr 30

17. Meier C, Dreher W, Leibfritz D. Diffusion in compartmental systems. I. A 
comparison of an analytical model with simulations. Magn Reson Med 2003;50:500-09

18. Kapur R, Sepahdari AR, Mafee MF, et al. MR imaging of orbital inflammatory syndrome, orbital cellulitis, and orbital lymphoid lesions: the role of diffusion-weighted imaging. AJNR Am J Neuroradiol 2009;30:64-70

19. Mathur S, Karimi A, Mafee MF. Acute optic nerve infarction demonstrated by diffusion-weighted imaging in a case of rhinocerebral mucormycosis. AJNR Am J Neuroradiol 2007;28:489-90

20. Rumboldt Z, Moses C, Wieczerzynski U, et al. Diffusion-weighted imaging, apparent diffusion coefficients, and fluid-attenuated inversion recovery MR imaging in endophthalmitis. AJNR Am J Neuroradiol 2005;26:1869-72

21. Hickman SJ, Wheeler-Kingshott CAM, Jones SJ, et al. Optic nerve diffusion measurement from diffusion-weighted imaging in optic neuritis. AJNR Am J Neuroradiol 2005;26:951-56

22. Lee AG, Johnson MC, Policeni BA, et al. Imaging for neuro-ophthalmic and orbita disease: a review. Clin Experiment Ophthalmol 2009;37:30-53. Epub 2008 Nov 5

23. Sepahdari AR, Aakalu VK, Setabutr P, et al. Indeterminate orbital masses: restricted diffusion at MR imaging with echo-planar diffusion-weighted imaging predicts malignancy. Radiology 2010;256:554-64

24. Politi LS, Forghani R, Godi C, et al. Ocular adnexal lymphoma: diffusionweighted MR imaging for differential diagnosis and therapeutic monitoring. Radiology 2010;256:565-74

25. Mishra AM, Gupta RK, Saksena S, et al. Biological correlates of diffusivity in brain abscess. Magn Reson Med 2005;54:878-85 